\title{
Investigation of the properties of biocomposite plasma coatings «titanium-magnesium-substituted calcium phosphates»
}

\author{
A. V. Lyasnikova, O. A. Dudareva ${ }^{\dagger}$ I. P. Grishina, O. A. Markelova, V. N. Lyasnikov \\ †kafbma2011@yandex.ru
}

Yuri Gagarin State Technical University of Saratov, 77 Politechnicheskaya st., Saratov, 410054, Russia

Complex investigations of the physical and chemical properties of coatings obtained by plasma spraying of magnesiumsubstituted hydroxyapatite and tricalcium phosphate powders on a titanium base have been carried out, and their comparative characteristics have been given. Infrared spectroscopy and X-ray phase analysis of substituted powders confirmed their structure. According to transmission electron microscopy, the powder particles of magnesium-substituted hydroxyapatite have an elongated shape, flat edges, the size of individual particles from $500 \mathrm{~nm}$ to $2-3 \mu \mathrm{m}$. The magnesium-substituted tricalcium phosphate powder is represented by particles of $300 \mathrm{~nm}$ to $7 \mu \mathrm{m}$ in size, nanometer-sized particles are cylinders, whereas larger particles have the shape of rectangular prisms. The magnesium-substituted tricalcium phosphate powder has specific surface indices in the range of $1-1.3 \mathrm{~m}^{2} / \mathrm{g}$, and the powder of magnesium-substituted hydroxyapatite has $42 \mathrm{~m}^{2} / \mathrm{g}$, which can indicate a high degree of development of the powder, as well as the presence of nano- and ultradisperse phases. Scanning electron microscopy of plasma sprayed coatings shows that a coating based on magnesium-substituted tricalcium phosphate, in contrast to magnesium-substituted hydroxyapatite, is formed by fine particles with clear boundaries that contribute to the formation of a more uniform microrelief. While a magnesium-substituted hydroxyapatite-based coating contains more micro- and nanoscale structural elements. The adhesion strength of the coating with the base in coatings based on magnesium-substituted hydroxyapatite is slightly higher than that of magnesium-substituted tricalcium phosphate. The calculated indices of adhesion for coatings based on magnesium-substituted hydroxyapatite are $14.9 \mathrm{MPa}$, and for a coating based on magnesium-substituted tricalcium phosphate, $13 \mathrm{MPa}$. The coatings under investigation are characterized by pronounced hydrophilic properties. The surface energy for both types of coating is determined primarily by the polar component, and not by the dispersion component, which indicates the presence of polar groups on the surface.

Keywords: substituted hydroxyapatite, substituted tricalcium phosphate, hydroxyapatite plasma spraying, biocomposite coatings.

УДК: 621.793

\section{Исследование свойств биокомпозитных плазменных покрытий «титан-магнийзамещенные кальцийфосфаты»}

\author{
Лясникова А. В., Дударева О. А. ${ }^{\dagger}$, Гришина И.П., Маркелова О. А., Лясников В. Н. \\ Саратовский государственный технический университет имени Ю.А. Гагарина, \\ ул. Политехническая, 77, Саратов, 410054, Россия
}

Проведены комплексные исследования физико-химических свойств покрытий, полученных плазменным напылением порошков магнийзамещенных гидроксиапатита и трикальцийфосфата на титановую основу, дана их сравнительная характеристика. Инфракрасная спектроскопия и рентгенофазовый анализ замещенных порошков подтвердили их структуру. По данным просвечивающей электронной микроскопии частицы порошка магнийзамещенного гидроксиапатита имеют вытянутую форму, плоские края, размер отдельных частиц от 500 нм до 2 - 3 мкм. Порошок магнийзамещенного трикальцийфосфата представлен частицами размером от 300 нм до 7 мкм, частицы нанометрового диапазона представляют собой цилиндры, тогда как более крупные частицы имеют форму прямоугольных призм. Порошок магнийзамещенного трикальцийфосфата обладает показателями удельной поверхности в пределах $1-1.3 \mathrm{~m}^{2} /$, а порошок магнийзамещенного гидроксиапатита $-42 \mathrm{~m}^{2} /$, что может говорить о высокой степени развитости порошка, а также о наличии нано- и ультрадисперсных фаз. Сканирующая электронная микроскопия плазменнонапыленных покрытий показывает, что покрытие на основе магнийзамещенного трикальцийфосфата в отличие от магнийзамещенного гидроксиапатита сформировано мелкими частицами, имеющими четкие границы, что способствует формированию более равномерного микрорельефа. В то время как покрытие на основе магнийза- 
мещенного гидроксиапатита содержит большее количество микро- и наноразмерных структурных элементов. Прочность сцепления с основой у покрытий на основе магнийзамещенного гидроксиапатита несколько выше, чем у магнийзамещенного трикальцийфосфата. Расчетные показатели адгезии для покрытий на основе магнийзамещенного гидроксиапатита - 14,9 МПа, а для покрытия на основе магнийзамещенного трикальцийфосфата - 13 МПа. Для исследуемых покрытий характерны выраженные гидрофильные свойства. Поверхностная энергия для обоих типов покрытия определяется преимущественно полярной составляющей, а не дисперсионной, что свидетельствует о присутствии на поверхности полярных групп.

Ключевые слова: замещенный гидроксиапатит, замещенный трикальцийфосфат, плазменное напыление, биокомпозитные покрытия.

\section{1. Введение}

Покрытия внутрикостных имплантатов должны обладать определенными структурно-морфологическими и физико-химическими характеристиками, в частности: обладать определенной пористостью $[1,2]$, гидрофильностью [3, 4], высокими адгезионными характеристиками $[5,6]$ и др. Также немаловажным фактором является наличие наночастиц в сформированном покрытии, которые могут способствовать процессам остеоинтеграции [7 - 9].

Использование технологии плазменного напыления позволяет добиться необходимых механических и морфологических характеристик покрытий [10], а применение различных порошков позволяет придать дополнительные свойства, например, повышенные адгезионные характеристики, антимикробный эффект и пр. [11, 12].

Интерес представляет формирование покрытий на основе магнийзамещенных порошковых кальцийфосфатов, а именно гидроксиапатита и трикальцийфосфата [13-16]. Степень замещения магнием в кальцийфосфатных порошках составляет до 23\%, он играет важную роль в биологической активности и взаимодействии между минеральной составляющей кости и кальцийфосфатным покрытием имплантата, оказывая влияние на скорость резорбции покрытия, химический состав поверхности, а также морфологию и механические свойства покрытий [17].

Перспективным представляется сравнение основных структурно-морфологических и физико-химических характеристик плазменных покрытий, сформированных на основе порошков магнийзамещенных гидроксиапатита (Mg-ГА) и трикальцийфосфата (Mg-ТКФ). Это связано с тем, что хотя гидроксиапатит и трикальцийфосфат относятся к одному типу керамики на основе фосфатов кальция [18], но покрытия на их основе обладают различными морфологическими и медико-биологическими характеристиками $[19,20]$.

Цели исследования: целью представленной работы являлся сравнительный анализ структурно-морфологических и физико-химических характеристик плазменнонапыленых покрытий на основе порошков $\mathrm{Mg}$-ГА и $\mathrm{Mg-TКФ.}$

\section{2. Материалы и методы}

Синтез $\mathrm{Mg}$-ГА проводился методом осаждения из водных растворов нитрата кальция, нитрата магния, диаммонийфосфата и гидроксида аммония [21] по реакции:

$$
\begin{gathered}
(10-x) \mathrm{Ca}\left(\mathrm{NO}_{3}\right)_{2}+x \mathrm{Mg}\left(\mathrm{NO}_{3}\right)_{2}+6\left(\mathrm{NH}_{4}\right)_{2} \mathrm{HPO}_{4}+8 \mathrm{NH}_{4} \mathrm{OH}= \\
=\mathrm{Ca}_{10-x} \mathrm{Mg}_{x}\left(\mathrm{PO}_{4}\right)_{6}(\mathrm{OH})_{2}+20 \mathrm{NH}_{4} \mathrm{NO}_{3}+6 \mathrm{H}_{2} \mathrm{O} \\
0.1 \leq x \leq 1.0
\end{gathered}
$$

Процесс проводился при температуре раствора $t=20^{\circ} \mathrm{C}, \mathrm{pH}$ раствора поддерживался на уровне $9-12$.

Синтез Mg-ТКФ проводился в 3 этапа: синтез $\beta$-ТКФ по стандартным методикам [18]; синтез пирофосфата магния (ПФМ); синтез Mg-ТКФ.

Для синтеза ПФМ стехиометрическое отношение $\mathrm{Mg} / \mathrm{P}$ взято 1,67 по аналогии с синтезом гидроксиапатита кальция. ПФМ и $\mathrm{Mg}$-ТКФ получали по реакциям:

$$
\begin{gathered}
\mathrm{Mg}^{2+}+\left(\mathrm{NH}_{4}\right)_{2} \mathrm{HPO}_{4}+\mathrm{NH}_{3}+6 \mathrm{H}_{2} \mathrm{O} \rightarrow \\
\rightarrow \downarrow \mathrm{MgNH}_{4} \mathrm{PO}_{4} \cdot 6 \mathrm{H}_{2} \mathrm{O}+2 \mathrm{NH}_{4}^{+} \\
\mathrm{MgNH}_{4} \mathrm{PO}_{4}+\mathrm{H}_{2} \mathrm{O} \rightarrow \mathrm{MgHPO}_{4}+2 \mathrm{NH}_{4} \mathrm{OH} \\
2 \mathrm{MgHPO}_{4} \stackrel{t}{\rightarrow} \mathrm{Mg}_{2} \mathrm{P}_{2} \mathrm{O}_{7}+\mathrm{H}_{2} \mathrm{O} \uparrow \\
2 \mathrm{MgNH}_{4} \mathrm{PO}_{4} \cdot 6 \mathrm{H}_{2} \mathrm{O} \stackrel{t}{\rightarrow} \mathrm{Mg}_{2} \mathrm{P}_{2} \mathrm{O}_{7}+7 \mathrm{H}_{2} \mathrm{O} \uparrow+2 \mathrm{NH}_{3} \uparrow \\
\mathrm{Mg}_{2} \mathrm{P}_{2} \mathrm{O}_{7}+\mathrm{CaCO}_{3} \stackrel{t}{\rightarrow} \mathrm{Mg}_{2} \mathrm{Ca}\left(\mathrm{PO}_{4}\right)_{2}+\mathrm{CO}_{2} \uparrow
\end{gathered}
$$

Осадок ПФМ, полученный в результате синтеза, оставляли на созревание на 24 часа в стакане. После отстаивания осадок $\mathrm{MgNH}_{4} \mathrm{PO}_{4}$ пятикратно промывали декантацией до рН 7 для его частичного гидролиза, фильтровали на воронке Бюхнера. Осадок сушили при температуре $95^{\circ} \mathrm{C}$ в течение суток, а затем в течение 2 часов при температуре $200^{\circ} \mathrm{C}$ и далее в течение 3 часов прокаливали порошок при температуре $600^{\circ} \mathrm{C}$ для придания ему более кристаллической структуры.

Рентгеноструктурный фазовый анализ синтезированных порошков проводился на дифрактометре Xcalibur/Gemini A c использованием рентгеновской трубки с медным анодом. Для анализа дифрактограмм применялась программная среда Match! 2003-2009 CRYSTAL IMPACT, Bonn, Germany с использованием баз данных American Mineralogist Crystal Structure Database (AMCSD) и Crystallography Open Database (COD).

Исследование ИК-спектров проводилось на Фурье-спектрометре FT-801 в интервале волновых чисел $500 . .4000 \mathrm{~cm}^{-1}$, таблетки с $\mathrm{KBr}$.

Исследование порошков проводилось методом просвечивающей электронной микроскопии (ПЭМ) с помощью микроскопа Libra-120 Carl Zeiss.

Определение удельной поверхности $\left(S_{\text {уд }}\right)$ и объема микропор порошков проводили методом низкотемпературной адсорбции азота по методу Брунауэра-ЭмметаТеллера на анализаторе удельной площади поверхности NOVA 2000e. 
Для формирования керамического покрытия применялась полуавтоматическая установка УПН-28. Покрытия формировались путем последовательного нанесения слоев порошка титана марки ВТ1-0 (для создания переходного слоя между компактным титаном и кальцийфосфатным покрытием) и слоев соответствующих металлзамещенных кальцийфосфатов. Для проведения сравнительного анализа основных физико-химических и механических свойств покрытия наносились при одинаковых режимах, а именно: ток дуги - 350 А, дисперсность порошка титана - 100-150 мкм, дисперсность магнийзамещенных порошков - до 90 мкм, расход плазмообразующего газа (аргон) - 20 л/мин, дистанция напыления порошка титана до 150 мм, дистанция напыления магнийзамещенных порошков до 50 мм.

Покрытие формировалось на образцах из титана марки ВТ1-0, представляющих собой цилиндры диаметром 6,5 мм и высотой 1,5 мм для исследования физикохимических параметров покрытий, и плоских образцах размером $10 \times 20 \times 2$ мм для исследования адгезионных характеристик покрытий.

Перед плазменным напылением образцы подвергались очистке и обезжириванию в установке ультразвуковой обработки «УЗУМИ-2» в водном растворе ПАВ при частоте 18 кГц в течение 5 мин; последующей воздушно-абразивной обработке на аппарате ACO3 1.2 МЕГА порошком электрокорунда Белэкт № 25 дисперсностью до 300 мкм в течение 10 мин.

Исследования морфологии и химического элементного состава поверхности проводились с использованием автоэмиссионного сканирующего электронного микроскопа MIRA 2 LMU производства фирмы Tescan, оснащенного системой энергодисперсионного микроанализа INCA Energy 350. Разрешающая способность микроскопа достигает 1 нм, а чувствительность детектоpa INCA Energy - 133 эВ/10 мм² $^{2}$

Адгезию плазменного покрытия определяли методом сдвига на испытательной универсальной машине ИР 5082-100 при скорости перемещения рабочей траверсы не более 0,5 мм/мин. Образцы склеивали напыленными поверхностями при помощи эпоксидного клея Henkel Loctite EA 3425, который выдерживает удельные нагрузки на разрыв до 40 МПа.

Оценку и измерение шероховатости поверхности проводили контактным методом с помощью профилографа-профилометра модели 170623.

Для оценки степени гидрофильности покрытий проводили измерение краевых углов смачивания с водой и глицерином методом лежащей капли с последующим расчетом свободной энергии поверхности по уравнению Оуэнса-Вендта.

\section{3. Результаты и обсуждение}

Проведенный рентгеноструктурный фазовый анализ порошка $\mathrm{Mg}$-ГА показал, что основной является фаза $\mathrm{Ca}_{95} \mathrm{MgP}_{7} \mathrm{O}_{28}$, при расшифровке данных для порошка $\mathrm{Mg}$-ТКФ была обнаружена фаза $\mathrm{Ca}_{2.81} \mathrm{Mg}_{0.19}\left(\mathrm{PO}_{4}\right)_{2}$, (Рис. 1a,b), что подтверждает внедрение частиц магния в структуру порошков. Также установлено, что в ре- зультате напыления порошки разлагаются на: $\mathrm{MgO}$; $\mathrm{CaMg}_{\sim 3}\left(\mathrm{CO}_{\sim 3}\right)_{\sim 4} ; \mathrm{Ca}_{9.5} \mathrm{MgP}_{7} \mathrm{O}_{28} ; \mathrm{Ca}_{3}\left(\mathrm{PO}_{4}\right)_{2} ; \mathrm{Mg}_{3}\left(\mathrm{PO}_{4}\right)_{2}$. В общем, можно констатировать, что магний оказывает дестабилизирующее действие на структуру кальцийфосфатов, что объясняется различием ионных радиусов кальция и магния $[18,22]$

ИК-анализ образцов $\mathrm{Mg}$-ГА показал, что частоты колебаний основных групп $\mathrm{PO}_{4}^{3-}, \mathrm{O}-\mathrm{P}-\mathrm{O}, \mathrm{OH}$, в основном соответствуют образцу синтетического ГА (Рис. 1с).

В ИК-спектре порошка Mg-ТКФ наблюдается интенсивная полоса валентных колебаний группы $\mathrm{PO}_{4}$ при $1100 \mathrm{~cm}^{-1}$. Полосы антисимметричных и симметричных валентных колебаний группы Р-O-P проявляются при 975 и $739 \mathrm{~cm}^{-1}$, соответственно (Рис. 1d).

По данным ПЭМ частицы порошка $\mathrm{Mg}$-ГА имеют вытянутую форму, плоские края, размер отдельных частиц от 500 нм до 2-3 мкм (Рис. 2a). Порошок Mg-ТКФ представлен частицами размером от 300 нм до 7 мкм, собранных в агломераты (Рис. 2b). Частицы нанометрового диапазона представляют собой цилиндры, тогда как форма более крупных частиц приближена к форме прямоугольного параллелепипеда.

Порошок Mg-ТКФ обладает показателями удельной поверхности в пределах $1-1.3 \mathrm{~m}^{2} /$, а порошок $\mathrm{Mg}$-ГА $42 \mathrm{M}^{2} /$ г. В свою очередь для большинства порошков металлов и неметаллов характерна поверхность от 0,01 до $1 \mathrm{~m}^{2} /$ г. Увеличение данных значений может говорить о высокой степени развитости (шероховатости) порошка, а также о наличии нано- и ультрадисперсных фаз.

Покрытия на основе порошка Mg-ГА сформированы частицами округлой формы размером 10-25 мкм с неровными краями. Также присутствуют микрокапли порошка размером 1 - 5 мкм и большие скопления наночастиц размером 100-250 нм (Рис. 3a).

Плазмонапыленное $\mathrm{Mg}$-ТКФ покрытие представлено частицами округлой формы размерами до 20 мкм, обнаруживаются проплавленные плоские частицы размером 30 - 90 мкм. На поверхности крупных частиц располагаются наночастицы размером 20 - 100 нм (Рис. 3b).

Покрытие на основе $\mathrm{Mg}$-ТКФ в отличие от $\mathrm{Mg}$-ГА состоит из мелких частиц, имеющих четкие границы, что способствует формированию более равномерного микрорельефа, но в свою очередь покрытие на основе $\mathrm{Mg-ГА} \mathrm{содержит} \mathrm{большее} \mathrm{количество} \mathrm{микро-} \mathrm{и} \mathrm{нанораз-}$ мерных структурных элементов.

Максимальное содержание магния в покрытиях на основе Mg-ГА составило 28 весовых \%, что несколько выше, чем в покрытиях на основе $\mathrm{Mg}$-ТКФ - 20 весовых \% (Табл. 1). Предположительно достаточно высокое содержание магния в Mg-ГА покрытии привело к большему прогреванию частиц в процессе плазменного напыления, их большему дроблению в результате столкновения с поверхностью основы, а как следствие, к формированию более развитого микрорельефа поверхности.

Расчетные показатели адгезии для $\mathrm{Mg}$-ГА покрытий $-14,9$ МПа, для Мg-ТКФ покрытий - 13 МПа. Прочность сцепления покрытия с основой у $\mathrm{Mg}$-ГА покрытий несколько выше, чем у $\mathrm{Mg}$-ТКФ, что по всей видимости связано с наличием на поверхности $\mathrm{Mg}$-ГА образцов большего количества микро- и наночастиц. 

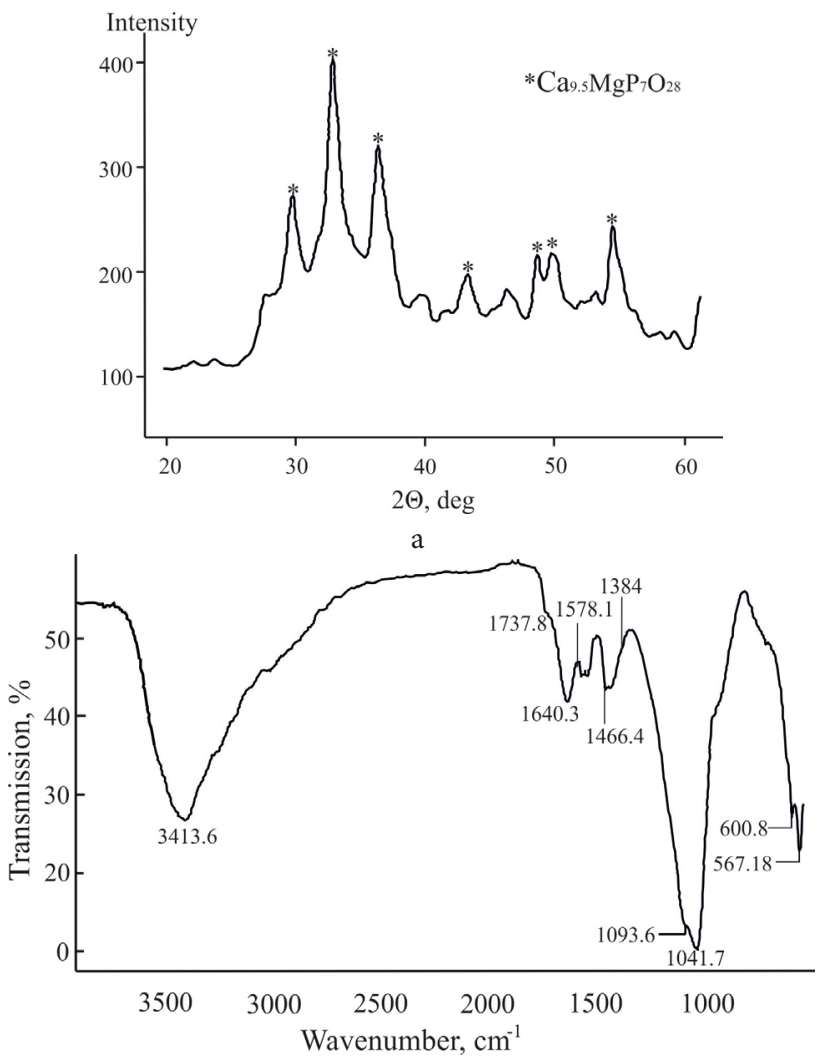

c

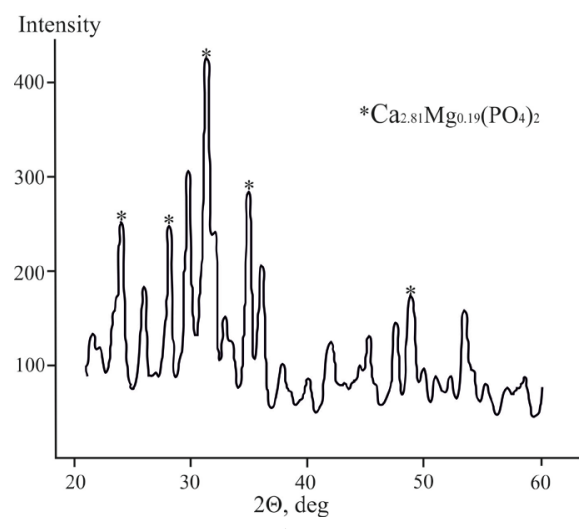

Optical density

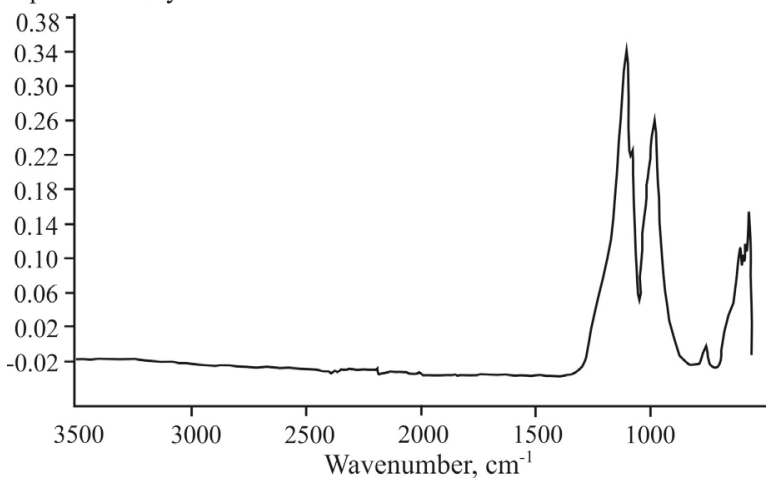

$\mathrm{d}$

Рис. 1. Результаты РФА и ИК-спектроскопии магнийзамещенных порошков: РФА порошка Mg-ГА (a); РФА порошка Мg-ТКФ (b); ИК-спектроскопия порошка $\mathrm{Mg}$-ГА (c); ИК-спектроскопия порошка $\mathrm{Mg}$-ТКФ (d).

Fig. 1. Results of XRF and IR spectroscopy of magnesium-substituted powders: RFA powder Mg-HA(a); RFA powder Mg-TKF (b); IR spectroscopy of Mg-HA powder (c); IR spectroscopy of Mg-TCP powder (d).
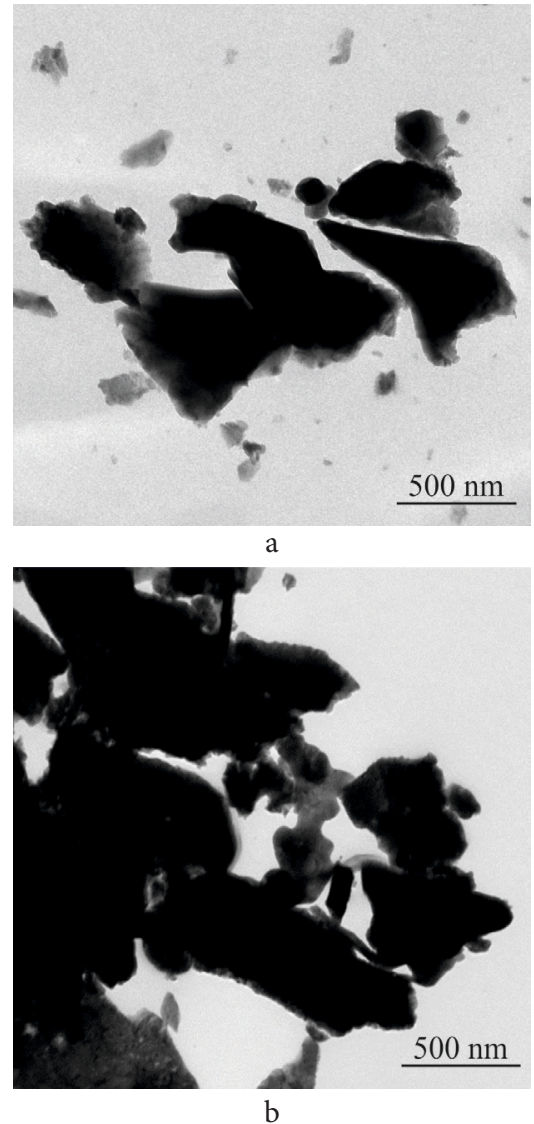

Рис. 2. ПЭМ Mg-ГА (a), Mg-ТКФ (b).

Fig. 2. TEM Mg-HA (a), Mg-TCP (b).

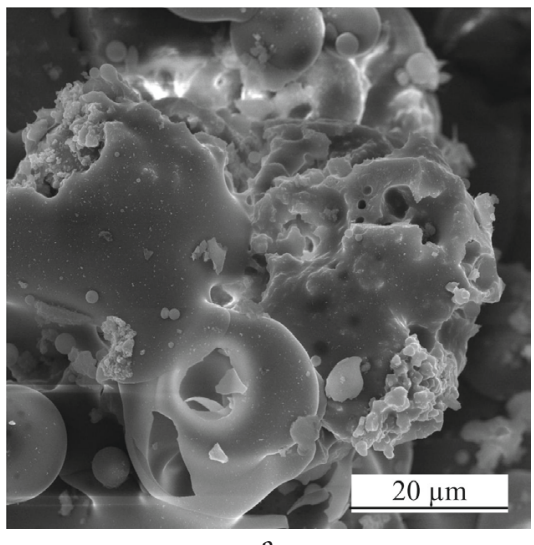

a

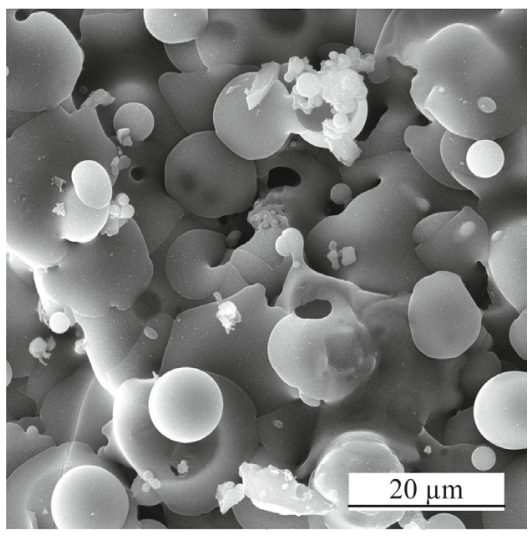

b

Pис. 3. СЭМ Mg-ГА (a), Mg-ТКФ (b) покрытий.

Fig. 3. SEM Mg-HA (a), Mg- TCP (b) coatings. 
Покрытие на основе Mg-ГА проявляет большие гидрофильные свойства по сравнению с Mg-ТКФ (Табл. 2), что также предположительно связано с различием морфологии поверхности покрытий. Оба типа покрытий проявляют гидрофильные свойства, что подтверждается значениями соответствующих контактных краевых углов [23]. Полученные результаты подтверждают перспективность использования покрытий на основе Mg-ГА и $\mathrm{Mg}$-ТКФ с целью повышения остеоинтеграционных параметров имплантатов.

\section{4. Заключение}

Методами РФА и ИК-спектроскопии подтверждена структура порошков магнийзамещенных гидроксиапатита (Mg-ГА) и трикальцийфосфата (Mg-ТКФ). Установлено, что частицы порошка Mg-ГА имеют форму вытянутых паралелпипедов размером от 500 нм до 3 мкм, частицы $\mathrm{Mg}$-ТКФ имеют размер от 300 нм до 7 мкм и собраны в агломераты. Плазмонапыленное $\mathrm{Mg}$-ТКФ покрытие в отличие от $\mathrm{Mg}$-ГА сформировано мелкими частицами, имеющими четкие границы, за счет чего формируется более равномерный микрорельеф, но в свою очередь покрытие на основе $\mathrm{Mg}$-ГА содержит большее количество микро- и нанообразований. Адгезия $\mathrm{Mg}$-ГА покрытий составила 14,9 МПа, Mg-ТКФ по- крытий - 13 МПа. Оба типа покрытий обладают гидрофильными свойствами.

На основании проведенных исследований и анализа литературных данных можно заключить, что полученные плазменные $\mathrm{Mg}$-ГА и $\mathrm{Mg}$-ТКФ покрытия весьма перспективны для применения в медицинской практике, в том числе в дентальной имплантологии и травматологии, благодаря достаточно высоким адгезионно-когезионным характеристикам и остеоинтеграционному потенциалу. В настоящее время авторами статьи проводятся комплексные медико-биологические испытания полученных порошков и покрытий на их основе in vitro и in vivo в соответствии с ГОСТ Р ИСО 10993-2009 «Оценка биологического действия медицинских изделий».

Благодарность/Aknowledgements. Исследование выполнено при финансовой поддержке Гранта Президента РФ МД-1403.2017.8, гранта РФФИ 16-08-01250 а. Авторы выражают благодарность проб. Пичхидзе С. Я. за синтез исходных порошков $M g$-ГА и $M g$-ТКФ./The reported study was funded by the Presidential Grant for the state support of young Russian scientists - PhDs MD-1403.2017.8 and RFBR according to the research project № 16-08-01250 a. The authors are grateful to prof. S. Pichhidze for synthesis of the $\mathrm{Mg}-\mathrm{HA}$ and $M g-T K$ powders.

Табл. 1. Элементный состав плазменнонапыленных покрытий (весовые \%).

Table 1. Elemental composition of the plasma of sprayed coatings (wt\%).

\begin{tabular}{|c|c|c|c|c|}
\hline $\begin{array}{l}\text { Номер спектра } \\
\text { Spectrum number }\end{array}$ & $\mathrm{O}$ & $\mathrm{P}$ & $\mathrm{Ca}$ & $\mathrm{Mg}$ \\
\hline \multicolumn{5}{|c|}{$\begin{array}{c}\text { Mg-ГА покрытие } \\
\text { Mg-НA coating }\end{array}$} \\
\hline 1 & 48 & 4 & 20 & 28 \\
\hline 2 & 50 & 4 & 18 & 28 \\
\hline 3 & 52 & 5 & 19 & 24 \\
\hline \multicolumn{5}{|c|}{$\begin{array}{c}\text { Mg-ТКФ покрытие } \\
\text { Mg-ТСР coating }\end{array}$} \\
\hline 1 & 39 & 17 & 24 & 20 \\
\hline 2 & 44 & 22 & 29 & 5 \\
\hline 3 & 48 & 21 & 24 & 7 \\
\hline
\end{tabular}

Табл. 2. Значения шероховатости и гидрофильности напыленных покрытий.

Table 2. The values of the roughness and hydrophilicity of the sprayed coatings.

\begin{tabular}{|c|c|c|c|c|c|c|}
\hline \multirow[b]{2}{*}{$\begin{array}{l}\text { Тип покрытия } \\
\text { Coating type }\end{array}$} & \multirow[b]{2}{*}{$\begin{array}{c}\text { Шероховатость, Ra, } \\
\text { мкм } \\
\text { Roughness, Ra, } \mu \mathrm{m}\end{array}$} & \multicolumn{2}{|c|}{$\begin{array}{l}\text { Краевой угол, град } \\
\text { Edge corner, degree }\end{array}$} & \multicolumn{3}{|c|}{$\begin{array}{c}\text { Поверхностная энергия, }\left(\times 10^{-3}\right) \mathrm{H} / \mathrm{M} \\
\text { Surface energy, }\left(\times 10^{-3}\right) \mathrm{N} / \mathrm{m}\end{array}$} \\
\hline & & $\begin{array}{l}\text { Вода } \\
\text { Аqua }\end{array}$ & $\begin{array}{c}\text { Глицерин } \\
\text { Glycerol }\end{array}$ & $\begin{array}{c}\text { Полная }(\sigma) \\
\text { Full }(\sigma)\end{array}$ & $\begin{array}{c}\text { Дисперсионная со- } \\
\text { ставляющая } \\
\text { The dispersion } \\
\text { component }\end{array}$ & $\begin{array}{l}\text { Полярная составляю- } \\
\text { щая } \\
\text { The polar component }\end{array}$ \\
\hline $\begin{array}{l}\mathrm{Mg}-\Gamma \mathrm{A} \\
\mathrm{Mg}-\mathrm{HA}\end{array}$ & 5,8 & 30,8 & 62,88 & 77,31 & 0,01 & 77,3 \\
\hline $\begin{array}{l}\text { Mg-ТК } \Phi \\
\text { Mg-ТСР }\end{array}$ & 4,2 & 30 & 67 & 69,4 & 1,8 & 67,6 \\
\hline
\end{tabular}




\section{Литература/References}

1. S. Durdu, K. Korkmaz, S. Aktug, A. Cakır. Surface and Coatings Technology. 326(15), Part A, 111 (2017). DOI: 10.1016/j.surfcoat.2017.07.039

2. B. Zheng, Y. Luo, H. Liao, C. Zhang. Journal of the European Ceramic Society. 37(15), 5017 (2017). DOI: 10.1016/j.jeurceramsoc.2017.07.007

3. C. Wen. Surface Coating and Modification of Metallic Biomaterials. Woodhead Publishing (2015) $448 \mathrm{p}$.

4. M. Nakamura, A. Kobayashi, K. Nozaki, N. Horiuchi, A. Nagai, K. Yamashita. Journal of Medical and Biological Engineering. 34(1), 44 (2014). DOI: 10.5405/jmbe. 1450

5. Y.C. Tsui, C. Doyle, T.W. Clyne. Biomaterials. 19(22), 2015 (1998). DOI: 10.1016/S0142-9612(98)00104-5

6. Z. Mohammadi, A.A. Ziaei-Moayyed, A.M. SheikhMehdi. Applied Surface Science. 253(11), 4960 (2007). DOI: 10.1016/j.apsusc.2006.11.002

7. R. Rojaee, M.H. Fathi, K. Raeissi. Advances in BioMechanical Systems and Materials. 40, 25 (2013). DOI: 10.1007/978-3-319-00479-2_3

8. S. Bose, S. Dasgupta, S. Tarafder, A. Bandyopadhyay. Acta Biomater. 6, 3782 (2010). DOI: 10.1016/j.actbio.2010.03.016

9. M.E. Iskandar, A. Aslani, H. Liu. J. Biomed Mater Res A., 101A, 2340 (2013). DOI: 10.1002/jbm.a.34530

10. A.V. Lyasnikova, O.A. Dudareva. Tekhnologiya sozdaniya mnogofunkcionalnyh kompozicionnyh pokrytij. Moscow, Speckniga (2012) 301 p. (in Russian) [Лясникова А. В., Дударева О. А. Технология создания многофункциональных композиционных покрытий: монография. Москва, Спецкнига (2012) 301 с.]

11. A. Wrona, K. Bilewska, M. Lis, M. Kaminska, T. Olszewski, P. Pajzderski, G. Więcław, M. Jaskiewicz, W. Kamysz. Surface and Coatings Technology. 318, 332 (2017). DOI: 10.1016/j.surfcoat.2017.01.101
12. A.V. Lyasnikova, O.A. Markelova, O. A. Dudareva, V.N. Lyasnikov, A.P. Barabash, S.P. Shpinyak. Powder Metallurgy and Metal Ceramics. 55(5-6), 328 (2016). DOI: $10.1007 / \mathrm{s} 11106-016-9809-9$

13. K. Salma-Ancane, L. Stipniece, A. Putnins, L. BerzinaCimdina. Ceramics International. 1(3), 4996 (2015). DOI: 10.1016/j.ceramint.2014.12.065

14. X. Zhang, T. Takahashi, K. S. Vecchio. Mater. Sci. Eng. 29, 2003 (2009). DOI: 10.1016/j.msec.2009.03.012

15. S.C. Cox, P. Jamshidi, L.M. Grover, K.K. Mallick. Materials Science and Engineering. 35, 106 (2014). DOI: $10.1016 /$ j.msec.2013.10.015

16. V.K. Mishra, B.N. Bhattacharjee, O. Parkash et al. J. Alloys and Compounds. 614, 283 (2014). DOI: $10.1016 /$ j.jallcom.2014.06.082

17. S. Kannan, J. Ferreira. Chem. Mater. 18(1), 198 (2006). DOI: $10.1021 / \mathrm{cm} 051966 \mathrm{i}$

18. S.M. Barinov, V.S. Komlev. Biokeramika na osnove fosfatov kalciya. Moscow, Nauka (2005) 204 p. (in Russian) [Баринов С. М., Комлев В.С. Биокерамика на основе фосфатов кальция. Москва, Наука (2005) 204 c.]

19. T. M. Lee, B. C. Wang, Y. C. Yang, E. Chang, C.Y. Yang. J Biomed Mater. Res. 55(3), 360 (2001).

20. R. Franca, T.D. Samani, G. Bayade, L. Yahia, E. Sacher. J Colloid Interface Sci. 15(420), 182 (2014). DOI: 10.1016/j.jcis.2013.12.055

21. Patent USA № 6921544, 06.03.2001. (in Russian) [Патент США №6921544. Способ получения кристаллического магний-замещенного гидроксиапатита, 06.03.2001.]

22. I.V. Fadeev, S.M. Barinov, L.I. Shvorneva, V.P. Orlovskii. Inorganic Materials. 39(9), 947 (2003). DOI: 10.1023/A:1025509305805

23. K. Webb, V. Hlady, P. A. Tresco. J. Biomed. Mater. Res. 241, 422 (1998). 